JPPKMI 2 (2) (2021)
JURNAL PENELITIAN DAN PENGEMBANGAN
KESEHATAN MASYARAKAT INDONESIA
Jttps://journal.unnes.ac.id/sju/index.php/jppkmi

\title{
Pelayanan Kesehatan, Pemilihan Kelas Perawatan dan Sanksi Layanan dengan Kemauan Membayar Premi (Willingness To Pay) Peserta Mandiri (PBPU)
}

\author{
Nilam Winda Amelia Wahyuni ${ }^{1} \bowtie$, Sri Widodo ${ }^{1}$ \\ ${ }^{1}$ Universitas Respati Indonesia, Indonesia
}

\section{Info Artikel}

Sejarah Artikel:

Diterima Agustus 2021

Disetujui Desember 2021

Dipublikasi Desember 2021

\section{Keywords:}

Willingness to Pay, PBPU

Participants, BPJS Health

URL:

https://iournal.unnes.ac.j d/sju/index.php/ippkmi /article/view/52428

\begin{abstract}
Abstrak
Target cakupan kesehatan semesta atau Universal High Coverage (UHC) menjamin seluruh masyarakat mempunyai akses untuk kebutuhan pelayanan kesehatan promotif, preventif, kuratif dan rehabilitatif yang berkualitas dan efektif. Dari data peserta mandiri di Provinsi DKI Jakarta sampai dengan bulan april tahun 2021 adalah sebanyak 994.859 jiwa atau sebesar $5,7 \%$ dan peserta mandiri (PBPU) yang menunggak sampai dengan bulan april tahun 2021 adalah sebanyak 256.954 jiwa atau sekitar $25.8 \%$ dari total kepesertaan mandiri (PBPU) di Provinsi DKI Jakarta. Peserta mandiri (PBPU) yang tidak dapat membayarkan kewajibannya setiap bulan maka penjaminan peserta diberhentikan sementara sampai dengan tanggal 1 bulan berikutnya. Sehingga jika terjadi tunggakan, peserta mandiri (PBPU) tidak dapat mengakses layanan BPJS Kesehatan. Tujuan Penelitian ini bertujuan untuk mengetahui pelayanan kesehatan, pemilihan kelas perawatan dan sanksi layanan dengan kemauan membayar (willingness to pay) peserta mandiri (PBPU) di Provinsi DKI Jakarta. Jenis penelitian yang digunakan adalah penelitian kuantitatif dengan desain cross sectional, dengan populasi penelitian sebanyak 112 Peserta Mandiri (PBPU) di Provinsi DKI Jakarta. Data diperoleh dengan menggunakan kuesioner dan dianalisis dengan menggunakan perangkat lunak statistik untuk uji chi square. Hasil Penelitian dalam penelitian ini menunjukan bahwa variabel pelayanan kesehatan dengan $p$ value $=0,013$ dan variabel sanksi layanan dengan $p$ value 0,042 yang artinya kedua variabel tersebut memiliki hubungan yang bermakna dengan kemauan membayar premi, sedangkan variabel pemilihan kelas perawatan memiliki $\mathrm{p}$ value $=1,00$ yang artinya tidak ada hubungan yang signifikan dengan dengan kemauan membayar premi. Saran dalam penelitian ini adalah Kepala Dinas Kesehatan dapat melakukan pembinaan dan pengawasan menjaga kualitas mutu dan layanan kesehatan di FKTP dan FKRTL agar peserta JKN dapat merasakan manfaat yang lebih maksimal dalam pelayanan kesehatan dan pemantauan terhadap Fasilitas Kesehatan yang meminta biaya atas layanan yang didapatkan peserta dan Kepada BPJS Kesehatan dapat memperpanjang program cicilan bagi peserta PBPU yang menunggak.
\end{abstract}

\footnotetext{
Alamat korespondensi:

Jl. Bambu Apus 1 No.3, Cipayung,

Jakarta Timur, 13890

E-mail: nilamwinda@gmail.com
} 


\section{PENDAHULUAN}

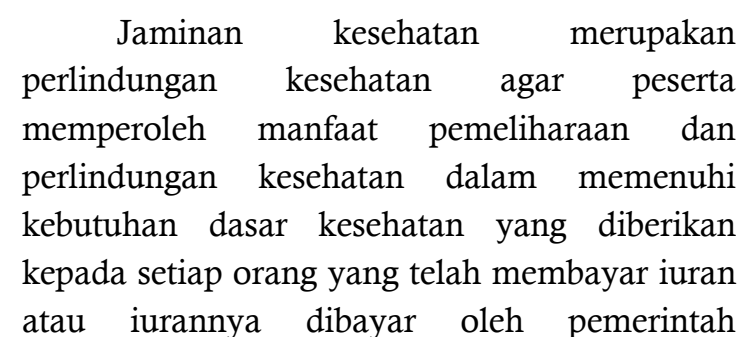
(Peraturan Presiden Republik Indonesia Nomor 12 Tahun 2013 Tentang Jaminan Kesehatan)

Berdasarkan data perkembangan cakupan kepesertaan BPJS Kesehatan menurut data dari BPJS Kesehatan, diketahui pada tahun 2014 mencapai 133.423.653 jiwa, tahun 2015 mendapat kenaikan sebesar $17,5 \%$ menjadi 156.790.287 jiwa pengguna BPJS Kesehatan. Tahun 2016 mengalami kenaikan lagi menjadi 171.939.254 jiwa, tahun 2017 sebanyak 187.982.949 jiwa dan tahun 2018 terdapat 208.054.199 jiwa dan terus meningkat sampai tahun 2019 sekitar 222.002.996 jiwa. Pada akhir tahun 2020 jumlah kepesertaan BPJS Kesehatan secara nasional adalah sekitar 222.461.906 jiwa atau sekitar $82,07 \%$ dari total cakupan keseluruhan penduduk (Sismonev Dewan Jaminan Sosial Nasional).

Target cakupan kesehatan semesta atau Universal High Coverage (UHC) menjamin seluruh masyarakat mempunyai akses untuk kebutuhan pelayanan kesehatan promotif, preventif, kuratif dan rehabilitatif yang berkualitas dan efektif. Di Provinsi DKI Jakarta, adapun target UHC dalam Rencana Pembangunan Jangka Menengah Daerah (RJPMD) Provinsi DKI Jakarta Tahun 20172022 dengan indikator program persentase penduduk DKI Jakarta yang memiliki jaminan kesehatan melalui Sistem Jaminan Sosial Nasional (SJSN) dengan target capaian tahun 2018 sampai dengan tahun 2021 adalah sebesar 95\% penduduk DKI Jakarta memiliki jaminan kesehatan dan pada akhir tahun 2022 dengan target $100 \%$ capaian seluruh penduduk DKI Jakarta sudah memiliki jaminan kesehatan (Dinas Kesehatan Provinsi DKI Jakarta, 2020)

Pemilihan kelas rawatan bagi peserta mandiri (PBPU) tentu saja berkaitan dengan kemampuan peserta mandri (PBPU) untuk membayar iuran setiap bulannya. Berdasarkan data dari Sismonev DJSN bulan April tahun 2021, total jumlah peserta mandiri (PBPU) adalah sebanyak 30.787.849 jiwa dengan urutan pemilihan kelasnya adalah pemilihan kelas rawatan 1 sebanyak 3.160 .984 jiwa (10,3\%), kelas rawatan II sebanyak 4.841 .614 jiwa $(15,7 \%)$ dan kelas rawatan III sebanyak 22.785.251 jiwa (74\%). Demikian juga dari data Sismonev DJSN Provinsi DKI Jakarta bulan April tahun 2021 dengan jumlah peserta mandiri (PBPU) sebanyak 994.859 jiwa dengan urutan pemilihan kelasnya adalah pemilihan kelas rawatan 1 sebanyak 289.733 jiwa (29,1\%), kelas rawatan II sebanyak 219.840 jiwa $(22,1 \%)$ dan kelas rawatan III sebanyak 485.286 jiwa $(48,8 \%)$. Dari data menunjukkan jumlah peserta mandiri (PBPU) hampir sebagian besar memilih kelas rawatan III yang merupakan iuran dengan nilai paling rendah.

Adapun akibat kelalaian peserta mandiri (PBPU) sehingga tidak dapat membayarkan kewajibannya setiap bulan maka akan dikenakan sanksi layanan sesuai dengan Peraturan Presiden Nomor 64 Tahun 2020 tentang perubahan kedua atas Peraturan Presiden Nomor 82 tahun 2018 tentang Jaminan Kesehatan (Peraturan Presiden Republik Indonesia Nomor 64 Tahun 2018 Tentang Jaminan Kesehatan, 2018) pada pasal 42 ayat (1) menyebutkan dalam hal peserta/pemberi kerja tidak membayar iuran sampai dengan akhir bulan berjalan maka penjaminan peserta diberhentikan sementara sampai dengan tanggal 1 bulan berikutnya. Dilanjutkan dalam pasal 42 ayat (3) dijelaskan jika status kepesertaan aktif kembali jika peserta telah melunasi iuran bulan tertunggak, paling banyak untuk waktu 24 bulan dan membayar iuran pada bulan pada saat peserta ingin mengakhiri pemberhentiaan sementara jaminan (Peraturan Presiden Republik Indonesia Nomor 82 Tahun 2018 Tentang Jaminan Kesehatan, 2018).

BPJS Kesehatan berupaya meningkatkan pengumpulan iuran peserta mandiri (PBPU) dengan beberapa cara, diantara nya melalui 
fasilitas autodebet bagi seluruh peserta mandiri (PBPU), mengirimkan sms blast untuk mengingatkan jatuh tempo pembayaran iuran, melalui tele-collection yaitu mengingatkan peserta mandiri (PBPU) melalui telpon, penagihan iuran oleh kader JKN, yang melibatkan masyarakat kepada peserta mandiri (PBPU) serta melalui crowd founding yang maksudnya menggunakan dana tanggungjawab perusahaan (CSR) dari perusahan besar untuk membantu membayarkan iuran peserta JKN disekitarnya.

Tujuan umum dari penelitian ini yaitu untuk mengetahui kemauan membayar premi (Wilingness to pay) peserta mandiri (PBPU) di Provinsi DKI Jakarta Tahun 2021. Sedangkan tujuan khusus dari penelitian ini Mengetahui hubungan pelayanan kesehatan dengan kemauan membayar premi (Wilingness to Pay) peserta mandiri (PBPU) di Provinsi DKI Jakarta, mengetahui hubungan pemilihan kelas rawatan dengan kemauan membayar premi (Wilingness to Pay) peserta mandiri (PBPU) di Provinsi DKI Jakarta dan Mengetahui hubungan sanksi layanan dengan kemauan membayar premi (Wilingness to Pay) peserta mandiri (PBPU) di Provinsi DKI Jakarta

\section{METODE}

Pendekatan yang digunakan dalam penelitian ini adalah penelitian kuantitatif. Sedangkan rancangan dalam penelitian menggunakan cross sectional yaitu suatu penelitian untuk mempelajari dinamika korelasi antara faktor-faktor risiko dengan efek, dengan cara pendekatan, observasi atau pengumpulan data (Notoatmodjo, 2010).

Penelitian ini dilakukan di 44 Puskesmas Kecamatan di Provinsi DKI Jakarta. Waktu Penelitian ini dilaksanakan pada bulan Juni 2021 sampai dengan Agustus 2021. Instrumen yang digunakan untuk pengambilan data dalam penelitian ini adalah kuesioner dengan hasil ukur skala 1-4 (tidak setuju, kurang setuju, setuju, sangat setuju).

Populasi dalam penelitian ini adalah seluruh peserta JKN Mandiri (PBPU) yang yang berada di wilayah kerja 44 Puskesmas
Kecamatan Provinsi DKI Jakarta. Penentuan jumlah sampel yang digunakan oleh penulis dalam penelitian ini adalah berdasarkan perhitungan lameshow sebagai alat ukur untuk menghitung ukuran sampel karena jumlah populasi yang diketahui lebih dari 100 responden [5]. Setelah dilakukan perhitungan, dapat diketahui bahwa sampel dalam penelitian ini agar dapat menjelaskan populasi yaitu minimal sebanyak 100. Tetapi, dikarenakan peneliti inginmeneliti di 44 puskesmas kecamatan maka setiap puskesmas mewakili 3 orang responden sehingga total sampel menjadi sebanyak 112 orang.

\section{HASIL DAN PEMBAHASAN}

Penyebaran kuesioner dibantu oleh masing-masing petugas puskesmas kecamatan di bagian loket pendaftaran yang berada di 44 kecamatan di provinsi DKI Jakarta. Kuesioner tersebut lalu diberikan kepada peserta mandiri (PBPU) yang berkunjung di seluruh Puskesmas Kecamatan wilayah Provinsi DKI Jakarta dalam bentuk google form.

Variabel independent terdiri dari 3 variabel yaitu pelayanan kesehatan, pemilihan kelas rawatan dan sanksi layanan. Sedangkan variabel dependent terdiri atas 1 variabel yaitu kemauan membayar premi (Willingness to pay) peserta mandiri (PBPU). Sedangkan variabel dependent terdiri atas 1 variabel yaitu kemauan membayar

Tabel 1. Distribusi Jawaban Responden Berdasarkan kemauan membayar premi

Kemauan membayar Frekuensi Persentase premi

\begin{tabular}{lll}
\hline Bersedia & 95 & 84.4 \\
Tidak bersedia & 17 & 15.2 \\
Total & 112 & 100 \\
\hline
\end{tabular}

Tabel 2. Distribusi Jawaban Responden kategori pelayanan kesehatan

\begin{tabular}{lll}
\hline Pelayanan Kesehatan & Frekuensi & Persentase \\
\hline Sesuai & 99 & 88.4 \\
Tidak Sesuai & 13 & 11.6 \\
Total & 112 & 100 \\
\hline
\end{tabular}


Tabel 3. Distribusi Jawaban Responden kategori Pemilihan Kelas Perawatan

\begin{tabular}{|c|c|c|c|}
\hline $\begin{array}{l}\text { Pemilihan } \\
\text { Perawatan }\end{array}$ & Kelas & Frekuensi & Persentase \\
\hline Susuai & & 11 & 98.2 \\
\hline Tidak Sesuai & & 2 & 1.8 \\
\hline Total & & 112 & 100 \\
\hline
\end{tabular}

Tabel 4. Distribusi Jawaban Responden kategori Sanksi Layanan

\begin{tabular}{lll}
\hline Sanksi Layanan & Frekuensi & Persentase \\
\hline Ada & 92 & 82.1 \\
Tidak Ada & 20 & 17.9 \\
Total & 112 & 100 \\
\hline
\end{tabular}

premi (Willingness to pay) peserta mandiri (PBPU).

Pada Tabel 1 Responden Berdasarkan distribusi jawaban responden tentang kemauan membayar premi (willingness to pay) peserta mandiri (PBPU) di Provinsi DKI Jakarta. Hampir sebanyak $84.4 \%$ responden bersedia membayar premi dan $15.2 \%$ tidak bersedia membayar premi.

Pada Tabel 2 Responden Berdasarkan distribusi jawaban responden tentang kategori pelayanan kesehatan, hampir $88.4 \%$ responden atau sebanyak 99 orang mendapatkan pelayanan kesehatan yang sesuai dan sebanyak $11.6 \%$ responden atau sebanyak 13 orang mendapatkan pelayanan kesehatan yang tidak sesuai.

Pada Tabel 3 Responden kategori pemilihan kelas perawatan di dapatkan bahwa $98.2 \%$ responden memilih kelas perawatan yang sudah sesuai dan hanya $1.8 \%$ responden yang merasa kelas perawtaan yang didapat tidak sesuai.
Pada Tabel 4 Responden Berdasarkan distribusi jawaban responden tentang sanksi layanan, didapatkan $82.1 \%$ responden setuju adanya sanksi layanan dan $17.9 \%$ responden tidak setuju adanya sanksi layanan.

Berdasarkan Tabel 5 Analisis Bivariat Hubungan pelayanan Kesehatan dengan Kemauan Membayar Premi (willingness to pay) peserta mandiri (PBPU) di Provinsi DKI Jakarta diatas, diketahui nilai odds ratio dengan CI 95\% memiliki value sebesar 4,531 atau sebesar 5 (pembulatan) artinya Pelayanan kesehatan mempengaruhi kemauan membayar premi sebesar 5 kali. Selain itu, dapat diketahui bahwa 13 reponden yang berpendapat pelayanan kesehatan yang didapat tidak sesuai, sebanyak 5 responden $(4.5 \%)$ tidak bersedia membayar premi dan 8 orang $(7.1 \%)$ bersedia membayar premi. Sedangkan dari 99 responden yang berpendapat pelayanan kesehatan yangdidapatkan sudah sesuai, sebanyak 12 responden(10.7\%) tidak bersedia membayar premi dan 87 responden $(77.7 \%)$ bersedia membayar premi. Selanjutnya diketahui hasil uji statistik $p$-value $0,013<0,05$ artinya adanya hubungan yang bermakna antara pelayanan kesehatan dengan kemauan membayar premi.

Berdasarkan Tabel 6 Hasil Analisis Bivariat Hubungan pemilihan kelas perawatan dengan Kemauan Membayar Premi (willingness to pay) peserta mandiri (PBPU) di Provinsi DKI Jakarta diatas, variable pemilihan kelas perawatan dengan variable kemauan membayar premi menunjukkan dari 2 reponden yang berpendapat pemilihan kelas perawatan tidak sesuai, terdapat sebanyak 0 responden $(0.0 \%)$ tidak bersedia membayar premi dan 2 orang $(1.8 \%)$ bersedia membayar premi. Sedangkan

Tabel 5. Hasil Analisis Bivariat Hubungan pelayanan Kesehatan dengan Kemauan Membayar Premi (willingness to pay) peserta mandiri (PBPU) di Provinsi DKI Jakarta.

\begin{tabular}{|c|c|c|c|c|c|c|c|c|}
\hline \multirow{3}{*}{$\begin{array}{l}\text { Pelayanan } \\
\text { Kesehatan }\end{array}$} & \multicolumn{4}{|c|}{ Kemauan Membayar Premi } & \multirow{2}{*}{\multicolumn{2}{|c|}{ Total }} & \multirow[t]{3}{*}{$P$ value } & \multirow{3}{*}{$\begin{array}{l}\text { OR } \\
(95 \% \\
\text { CI) }\end{array}$} \\
\hline & \multicolumn{2}{|c|}{ Tidak Bersedia } & \multicolumn{2}{|c|}{ Bersedia } & & & & \\
\hline & $\mathrm{n}$ & $\%$ & $\mathrm{n}$ & $\%$ & $\mathrm{n}$ & $\%$ & & \\
\hline Tidak ada & 5 & 4.5 & 8 & 7.1 & 13 & 11.6 & 0.013 & 4.531 \\
\hline Ada & 12 & 10.7 & 87 & 77.7 & 99 & 88.4 & & \\
\hline Jumlah & 17 & 15.2 & 95 & 84.8 & 112 & 100 & & \\
\hline
\end{tabular}


Tabel 6. Hasil Analisis Bivariat Hubungan pemilihan kelas perawatan dengan Kemauan Membayar Premi (willingness to pay) peserta mandiri (PBPU) di Provinsi DKI Jakarta.

\begin{tabular}{|c|c|c|c|c|c|c|c|c|}
\hline \multirow{3}{*}{$\begin{array}{l}\text { Pemilihan } \\
\text { Kelas } \\
\text { Perawatan }\end{array}$} & \multicolumn{4}{|c|}{ Kemauan Membayar Premi } & \multirow{2}{*}{\multicolumn{2}{|c|}{ Total }} & \multirow[t]{3}{*}{$\mathrm{P}$ value } & \multirow{3}{*}{$\begin{array}{l}\text { OR } \\
(95 \% \\
\text { CI) }\end{array}$} \\
\hline & \multicolumn{2}{|c|}{ Tidak Bersedia } & \multicolumn{2}{|c|}{ Bersedia } & & & & \\
\hline & $\mathrm{n}$ & $\%$ & $\mathrm{n}$ & $\%$ & $\mathrm{n}$ & $\%$ & & \\
\hline Tidak ada & 0 & 0.0 & 2 & 1.8 & 2 & 1.8 & 1 & - \\
\hline Ada & 17 & 15.2 & 93 & 83.0 & 110 & 98.2 & & \\
\hline Jumlah & 17 & 15.2 & 95 & 84.8 & 112 & 100 & & \\
\hline
\end{tabular}

dari 110 responden yang berpendapat pemilihan kelas perawtaan sudah sesuai, sebanyak 17 responden(15.2\%) tidak bersedia membayar premi dan 93 responden $(83.0 \%)$ bersedia membayar premi.

Pada pengujian bivariate menggunakan analisa chi square, menunjukkan hasil dari P.value sebesar 1, yang artinya P.value $>0.05$ sehingga tidak adanya adanya hubungan yang bermakna antara pemilihan kelas perawatan dengan kemauan membayar premi. Berdasarkan Tabel 7 Hasil Analisis Bivariat Sanksi Layanan dengan Kemauan Membayar Premi (willingness to pay) peserta mandiri (PBPU) di Provinsi DKI Jakarta diatas, diketahui nilai odds ratio dengan CI $95 \%$ memiliki value sebesar 3,156 artinya responden yang berpendapat adanya sanksi layanan mempunyai peluang 3 kali memiliki kemauan membayar premi dibandingkan responden yang berpendapat tidak adanya sanksi layanan. hasil tabulasi silang antara variable sanksi layanan dengan variable kemauan membayar premi menunjukkan dari 20 reponden yang berpendapat tidak adanya sanksi, sebanyak 6 responden (5.4\%) tidak bersedia membayar premi dan 14 orang $(12.5 \%)$ bersedia membayar premi. Sedangkan dari 92 responden yang berpendapat adanya sanksi layanan, sebanyak 11 responden(9.8\%) tidak bersedia membayar premi dan 81 responden $(72.3 \%)$ bersedia membayar premi.

Pada pengujian bivariate menggunakan analisa chi square, menunjukkan hasil dari P.value sebesar 0.042 , yang artinya P.value < 0.05 sehingga adanya hubungan yang bermakna antara sanksi layanan dengan kemauan membayar premi.

Kemauan Membayar Premi (Willingness to pay) Peserta Mandiri (PBPU) di Provinsi DKI Jakarta Hasil penelitian Kemauan Membayar Premi (Willingness to pay) Peserta Mandiri (PBPU) di Provinsi DKI Jakarta menggunakan uji chi Square pada tabel 5.5 berdasarkan hasil perhitungan total skor secara keseluruhan dapat diketahui sebanyak 95 orang (84.8\%) memiliki kategori bersedia dalam kemauan membayar premi, sedangkan 17 orang (15.2\%) memiliki kategori tidak bersedia dalam kemauan membayar premi.

Kemauan membayar masyarakat tentu tidak terlepas dari faktor-faktor yang mempengaruhi. Hasil penelitian ini sejalan dengan penelitian sebelumnya, di Malaysia kemauan membayar yang lebih besar untuk bergabung dengan jaminan kesehatan pada masyarakat yang sudah menikah dan

Tabel 7. Hasil Analisis Bivariat Sanksi Layanan dengan Kemauan Membayar Premi (willingness to pay) peserta mandiri (PBPU) di Provinsi DKI Jakarta.

\begin{tabular}{|c|c|c|c|c|c|c|c|}
\hline \multirow{3}{*}{$\begin{array}{l}\text { Sanksi } \\
\text { Layanan }\end{array}$} & \multicolumn{3}{|c|}{ Kemauan Membayar Premi } & \multirow{2}{*}{\multicolumn{2}{|c|}{ Total }} & \multirow[t]{3}{*}{$\mathrm{P}$ value } & \multirow{3}{*}{$\begin{array}{l}\text { OR } \\
(95 \% \\
\text { CI) }\end{array}$} \\
\hline & Tidak Bersedia & \multicolumn{2}{|c|}{ Bersedia } & & & & \\
\hline & $\%$ & $\mathrm{n}$ & $\%$ & $\mathrm{n}$ & $\%$ & & \\
\hline Tidak & 5.4 & 14 & 12.5 & 20 & 17.9 & 0.042 & 3.156 \\
\hline
\end{tabular}

ada 


\begin{tabular}{lllllll} 
Ada & 11 & 9.8 & 81 & 72.3 & 92 & 82.1 \\
Jumlah & 17 & 15.2 & 95 & 84.8 & 112 & 100 \\
\hline
\end{tabular}

berpendidikan lebih tinggi Dan factor lainnya yang mempengaruhi adalah pendapatan perbulan, pendidikan serta status perkawinan juga merupakan salah satu factor yang mempengaruhi dalam membayar iuran program jaminan kesehatan masyarakat di Malaysia. (Yandrizal, 2015). Penelitian lainnya menunjukkan hubungan yang bermakna

antara mutu pelayanan kesehatan dengan kemauan membayar $(\mathrm{p}=0,036)$.

Dari hasil penelitian ini, sebahagian besar peserta mandiri (PBPU) yang bersedia membayar premi dikarenakan pelayanan kesehatan yang baik yang didapatkan oleh responden, fasilitas pelayanan yang baik serta manfaat dari program jaminan kesehatan yang dirasakan manfaatnya oleh responden.

Hubungan Pelayanan Kesehatan dengan Kemauan Membayar Premi (Willingness to pay) Peserta Mandiri (PBPU) di Provinsi DKI Jakarta

Menurut hasil penelitian tersebut menunjukkan hampir semua responden sebanyak 99 orang (88.4\%) mendapatkan pelayanan kesehatan yang sesuai dan sebanyak 13 orang (11.6\%) mendapatkan pelayanan kesehatan yang tidak sesuai. Hal ini sesuai dengan yang dijelaskan oleh (Syukron \& Hasan, 2015), bahwa Mutu pelayanan kesehatan jika dinilai dengan baik apabila suatu pelayanan kesehatan yang diselenggarakan dapat menimbulkan rasa senang atau rasa puas pada diri setiap pasien yang sesuai dengan tingkat kepuasan rata-rata penduduk atau masyarakat yang menjadi suatu sasaran utama dalam pelayanan kesehatan.

Pelayanan kesehatan tidak terlepas dalam lima prinsip dimensi pelayanan sebagai ukurannya, yaitu Responsiveness (daya tanggap), reability (keandalan), assurance (jaminan), empathy (empati) dang tangible (bukti lansung) (Fitzsimmons, 2011).

Dan dari tabel 5.13 dapat diketahui hasil tabulasi silang antara pelayanan kesehatan dengan kemauan membayar premi yang hasilnya menunjukkan dari 13 reponden yang berpendapat pelayanan kesehatan yang didapat tidak sesuai, sebanyak 5 responden (4.5\%) tidak bersedia membayar premi dan 8 orang $(7.1 \%)$ bersedia membayar premi. Sedangkan dari 99 responden yang berpendapat pelayanan kesehatan yangdidapatkan sudah sesuai, sebanyak 12 responden(10.7\%) tidak bersedia membayar premi dan 87 responden (77.7\%) bersedia membayar premi. Hasil penelitian ini berbanding lurus dan sangat berpengaruh antara pelayanan kesehatan yang didapatkan dengan kemauan pesreta dalam membayar premi.

Hal ini sejalan dengan penelitian Erlita Noviana Sihaloho (2015), dimana dalam determinan kemauan membyara iuran peserta jaminan kesehtaan nasional mandiri di wilayah kerja Dinas Kesehatan Kota Semarang didapatkan mutu pelayanan kesehatan memiliki hubungan yang signifikan $(\mathrm{p}=0,012)$. Pelayanan kesehatan yang baik tentu akan memberikan pengaruh kepada peserta jaminan kesehatan nasional dalam membayar premi sehingga dengan pelayanan maksimal yang didapatkan peserta maka dapat meningkatkan kemauan peserta membayar premi (Willingness to pay). Pelayanan kesehatan tidak terlepas dari 5 dimensi mutu, yaitu pelayanan kesehatan yang cepat tanggap,petugas yang handal, pelayanan kesehatan yang diberikan memiliki jaminan, adanya empati dari petugas kesehatan serta didukung oleh fasilitas pelayanan yang baik. Dalam penelitian ini responden hampuir sebagian besar menilai pelayanan kesehatan yang di dapat sudah sesuai. Namun ada beberapa responden yang menilai dalam memberikan pelayanan kesehatan petugas tidak memberikan rujukan sesuai keadaan pasien serta biaya yang di pungut tidak sesuai dengan ketentuan. Hal ini tentu saja pelayan kesehatan harus menjelaskan kepada pasien bahwa tidak semua pengobatan mendapatkan rujukan lanjutan dan jika hendak berobat tentunya sesuai dengan fasiltas kesehatan yang terdaftar 
pada peserta sehingga peserta tidak mengeluarkan biaya tambahan dalam pelayanan kesehatan.

Hubungan Kelas Perawatan dengan Kemauan Membayar Premi (Willingness to pay) Peserta Mandiri (PBPU) di Provinsi DKI Jakarta

Hasil analisis bivariate dengan menggunakan uji chi square, variable Pemilihan Kelas Perawatan didapatkan nilai P.value $=1(\mathrm{p}$ $>0.05)$. dengan demikian dapat disimpulkan bahwa tidak adanya pengaruh yang bermakna atau signifikan antara pemilihan kelas perawatan dengan kemauan membayar premi (Willingness to pay) peserta mandiri (PBPU) di Provinsi DKI Jakarta.

Walaupun hasil tabulasi silang tersebut dianggap tidak bermakna atau tidak signifikan berpengaruh namun berdasarkan hasil distribusi frekuensi, sebenarnya dapat kita lihat antara pemilihan kelas perawatan yang sesuai maka tidak adanya tunggakan dalam membayar premi. Responden didalam hasil penelitian mengenai harga premi yang saat ini tidak memberatkan peserta maka sebagian besar peserta merasa keberatan dengan pertanyaan tersebut atau sebanyak 74 responden menyatakan bahwa harga premi saat ini memberatkan responden. Beberapa responden yang mengalami tunggakan dalam membayar premi juga menjelaskan bahwa mereka tidak terinformasi bagaimana cara mencicil tunggakan yang dimiliki saat ini.

Hal ini sejalan dengan penelitian yang dilakukan oleh (Indriani, 2020) menjelaskan bahwa tidak ada hubungan yang bermakna antara kemauan mebayar dengan keputusan kelas iuran BPJS Kesehatan. Dengan demikian walaupun hasil uji statistic yang dilakukan tidak memiliki hubungan terkait kemauan membayar premi namun pada kenyataannya pemilihan kelas perawatan tentu saja membutuhkan komitmen dan kemauan dari responden untuk membayar premi tepat waktu sehingga tidak terjadi tunggakan.

Hubungan Sanksi Layanan dengan Kemauan Membayar Premi (Willingness to pay) Peserta Mandiri (PBPU) di Provinsi DKI Jakarta
Hasil analisis bivariate dengan menggunakan uji chi square, variable pelayana kesehatan didapatkan nilai P.value $=0.042(\mathrm{p}<$ 0.05). dengan demikian dapat disimpulkan bahwa adanya pengaruh yang bermakna atau signifikan antara sanksi layanan dengan kemauan membayar premi (Willingness to pay) peserta mandiri (PBPU) di Provinsi DKI Jakarta.

Sanksi merupakan aktual dari norma hukum yang mempunyai karakteristik sebagai ancaman atau sebagai sebuah harapan. Sanksi akan memberikan dampak positif atau negatif terhadap lingkungan sosialnya. Disamping itu sanksi (punishment) merupakan pemberian hasil yang tidak diinginkan (menyakitkan) untuk meminimalisir perilaku yang tidak diinginkan. (Sahwitri, 2014). Keterlambatan pembayaran iuran jaminan kesehatan disebabkan kelalaian atas ketidaktepatan waktu pembayaran iuran sebagaimana yang di atur di dalam Perpres Nomor 19 tahun 2016 tentang Jaminan Kesehatan Nasional, dimana maka peserta tidak akan dikenakan denda atau apapun karena telat membayar iuran, hanya saja pemerintah menyiapkan 2 (dua) sanksi yaitu :

1) Peserta BPJS yang menunggak status kepesertaannya akan menjadi tidak aktif atau dihentikan sampai peserta yang bersangkutan melunasi tunggakan atau tagihan iuran. Jika tunggakan mencapai 6 bulan atau 1 tahun maka pembayaran untuk pelunasan harus dilakukan di kantor BPJS Kesehatan, setelah tagihannya lunas maka status kepesertaan akan aktif kembali.

2) Peserta tidak diperkenankan (dilarang) menggunakan layanan BPJS Kesehatan dalam jangka waktu 45 hari sejak pelunasan. Jika peserta tetap menggunakan layanan BPJS Kesehatan sebelum 45 hari sejak pelunasan maka akan dikenakan denda pelayanan sebesar 5\% dari biaya paket Indonesian Case based Groups (Ina-cbg's) dengan ketentuan :

a) Jumlah bulan tertunggak paling banyak 12 (dua belas) bulan dan

b) Denda paling tinggi Rp. 30.000.000,00 (tiga puluh juta rupiah) 
Dengan adanya sanksi layanan terkait pembiayaan JKN hal ini menyebabkan peserta berkeinginan membayar iuran tepat waktu sehingga tidak mendapatkan masalah dalam pelayanan kesehatan nantinya. Artinya dari data yang didapatkan, semakin adanya sanksi layanan maka menyebabkan peserta menjadi mau untuk membayar premi tepat waktu sehingga tidak menimbulkan tunggakan. Namun beberapa responden merasa premi yang di bayarkan memberatkan, tentu saja ini menjadi salah satu hal yang menyebabkan timbulnya tunggakan bagi peserta mandiri.

\section{PENUTUP}

Berdasarkan hasil penelitian tentang pelayanan kesehatan, pemilihan kelas perawatan dan sanksi layanan terhadap kemauan membayar premi (Willingness to Pay) Peserta PBPU di Provinsi DKI Jakarta yang telah dilakukan. Kesimpulan pada penelitian ini yaitu kemauan membayar premi peserta mandiri (PBPU) sebanyak 84.8\% memiliki kategori bersedia dalam membayar premi, dan sebanyak 91 orang $(81.2 \%)$ peserta bersedia mencicil tunggakan yang ada jika BPJS Kesehatan memiliki program cicilan. Dari hasil penelitian responden bersedia membayar premi dikarenakan pelayanan kesehatan yang baik yang didapatkan responden, fasilitas pelayanan yang baik serta manfaat dari program jaminan kesehatan yang dirasakan oleh responden. Adanya hubungan pelayanan kesehatan dengan kemauan membayar premi (Willingness to pay) peserta mandiri (PBPU) di Provinsi DKI Jakarta dimana hampir semua responden sebanyak 99 orang (88.4\%) mendapatkan pelayanan kesehatan yang sesuai. Namun dari hasil penelitian sebanyak 19 orang (17\%) responden berpendapat masih mengeluarkan biaya atas layanan yang didapatkan. Tidak adanya pengaruh yang bermakna atau signifikan antara pemilihan kelas perawatan dengan kemauan membayar premi (Willingness to pay) peserta mandiri (PBPU) di Provinsi DKI Jakarta. Hasil penelitian didapatkan 110 responden memilih kelas perawatan yang sesuai namun sebanyak 93 orang $(83 \%)$ bersedia membayar premi dan sebanyak 17 orang (15.2\%) tidak bersedia membayar premi. Adanya hubungan yang bermakna atau signifikan antara sanksi layanan dengan kemauan membayar premi (Willingness to Pay) peserta PBPU di Provinsi DKI Jakarta dimana 81 responden $(72.3 \%)$ bersedia membayar premi dan setuju dengan adanya sanksi layanan.

Sehubungan dengan adanya regulasi terkait mekanisme membayar iuran bulan yang tertunggak pada tahun 2020 yang menyebabkan status kepesertaan Peserta menjadi tidak aktif, maka diharapkan BPJS Kesehatan dapat memperpanjang program cicilan yang ada. Dari hasil penelitian terdapat 91 orang (81.2\%) peserta bersedia mencicil tunggakan yang ada jika BPJS Kesehatan memiliki program cicilan. Dinas Kesehatan beserta jajaran perlu melakukan pembinaan dan pengawasan untuk menjaga kualitas mutu layanan kesehatan baik di FKTP maupun di FKRTL agar peserta JKN dapat merasakan manfaat yang lebih maksimal dalam pelayanan kesehatan. Dinas Kesehatan juga perlu melakukan pemantauan terhadap fasilitas kesehatan yang meminta biaya atas layanan yang di dapatkan peserta. Saran untuk peneliti selanjutnya yaitu agar dapat dilakukan penelitian yang sejenis dengan cakupan variabel yang lebih luas lagi, misalnya terkait variabel kemampuan membayar (Ability to Pay).

\section{DAFTAR PUSTAKA}

Binsar, Yusuf Sabilu, Rahman. 2020. Faktor Yang Berhubungan Dengan Kemauan Membayar (Willingness To Pay) IUran Peserta JKN MAnsiri di Wilayah Kerja Puskesmas Nambo Kota Kendari. Jurnal Administrasi Kebijakan Kesehatan (JAKK-UHO), 1(3)

Dinas Kesehatan Provinsi DKI Jakarta. 2020. Profil Dinas Kesehatan Provinsi DKI Jakarta Tahun 2020

Erlita Noviana Sihaloho. 2015. Determinan Kemauan Membayar Iuran Peserta Jaminan Kesehatan Nasional Mandiri di Wilayah Kerja Dinas Kesehatan Kota Semarang. Skripsi. Universitas Negeri Semarang 
Fitzsimmons, James A., and Mona J. Fitzsimmons. 2011. Service Management: Operations, Startegy, Infromation Technology (7th ed.). New York, NY: McGraw-Hill.

Indriani Syahkila, Nurgahayu, Ulfa Sulaeman. 2020.

Faktor Yang Berhubungan Dengan ATP dan WTP dengan Penentuan Keputusan Kelas Iuran BPJS Kesehatan. Skripsi. Window Of Public Health Journal, 10(5).

Notoatmodjo, S. 2010. Metodologi Penelitian Kesehatan. Jakarta : Rineka Cipta.

Peraturan Presiden Republik Indonesia Nomor 12 Tahun 2013 Tentang Jaminan Kesehatan

Peraturan Presiden Republik Indonesia Nomor 64 Tahun 2018 Tentang Jaminan Kesehatan
Peraturan Presiden Republik Indonesia Nomor 82 Tahun 2018 Tentang Jaminan Kesehatan

Sahwitri Triandani. 2014. Pengaruh Tim Kerja, Stres Kerja dan Reward (Imbalan). Pekanbaru. LPPM h.39

Sismonev Dewan Jaminan Sosial Nasional, http://sismonev.disn.go.id Diakses pada tanggal 28 Mei 2021 pada pukul 13.30 WIB Sugiyono. 2013. Metodelogi Penelitian Kuantitatif, KualitatifDan R\&D. Bandung: Alfabeta

Yandrizal Rifa'i, Utami, Selpa Putri. 2017. Analisis Kemampuan dan Kemauan Membayar Iuran Terhadap Pencapaian UHC di Kota Bengkulu, Jurnal Kesehatan Masayarakat Andalas. Padang, 10 (3). 